\title{
The Young Minds Leadership Meeting 2021 a virtual experience
}

\author{
॥ Richard Zeltner, Hripsime Mkrtchyan \& Carmen Martín Valderrama \\ I EPS YM Action Committee - DOI: https://doi.org/10.1051/epn/2021401 \\ The Young Minds (YM) programme of the European Physical Society (EPS) was \\ initiated 10 years ago, with the goal to connect young students and researchers all over \\ Europe and to support their professional and personal growth.
}

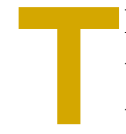

he programme now comprises more than $60 \mathrm{sec}$ tions being active in over 30 countries. A highlight of the annual agenda of YM is the leadership meeting, which is hosted by a section and brings delegates from all over the YM network together. The still high-case numbers and the dynamic situation in Europe regarding the Coronapandemic made a physical meeting in 2021 impossible, such that the meeting was transferred into the virtual realm. Given the large number of delegates attending, as well as the many lively and open discussions that took place, the meeting on May 7 can be considered a large success.

A big advantage of the virtual format was that no budget or logistical restrictions limited the number or availability of participants. Consequently, the meeting was open to anyone in the YM network and eventually attracted 55 section delegates, representing more than 30 sections and 21 countries from Europe and the Mediterranean. The delegates came from various career levels, ranging from bachelor students to postdocs.

Traditionally, the meeting comprises two parts: a part focused on professional development, and a part devoted to stimulating exchange and networking among the attendees. Hence the virtual meeting was divided into two parts as well, the first taking place on Zoom and the second part on the

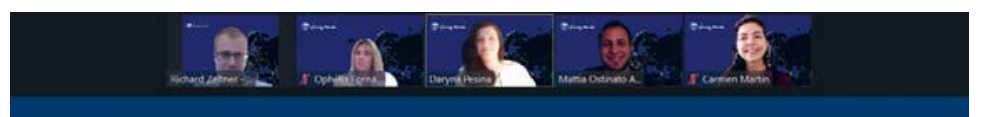

\section{Welcome}

to the EPS YM Leadership meeting 2021

32 sections.

21 countries.

Great to have you here (-)

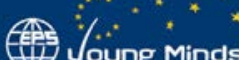

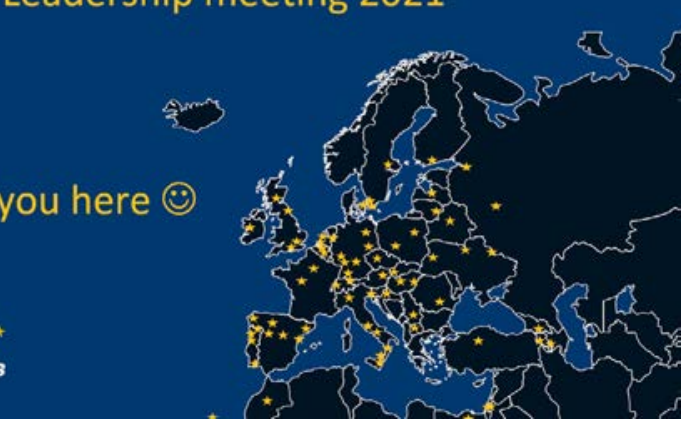

more interactive platform Gather Town. On Zoom EPS YM programme manager Ophélia Fornari welcomed the participants, gave a brief overview of the history of EPS YM, and described the new functionalities for section management on the EPS website to the participants. Her presentation was followed by Richard Zeltner, EPS YM Action Committee Chair, who gave a wrap-up on the years 2020 and 2021 from the YM perspective and highlighted the numerous section activities that were carried out despite the ongoing pandemic. Since the meeting was the first of its kind for several new sections that were created during the pandemic, he also gave a quick overview of the grant application process and the ways YM sections can share their work with the broader physics community in Europe, e.g. via publishing in e-EPS or EPN. He also gave an outlook on the plans for the rest of the year and 2022 and thanked the members of the Action Committee that left the programme over the course of the last two years, in particular Petra Rudolf who handed over the EPS presidency, and thus the position in the YM Action Committee, just in April. As the third speaker, Luc Bergé, current EPS president, presented the agenda for his presidency and his plan to establish the EPS Forum to the YM community. Since a majority of young physicists eventually pursue a career in the private industry sector, his explanations on his plans to strengthen the relationships between EPS and the industry were followed with great interest by the audience. Eventually the first part of the meeting was concluded by a panel discussion on career advice for young scientists. Our distinguished guests Dr. Gabrielle Thomas, Dr. Lucia Santamaria, Dr. Luc Bergé, Dr. Chang Kee Jung and Dr. Petra Rudolf brought a very diverse set of experiences and backgrounds to the table. The open discussion on topics ranging from the role of professional media platforms for personal branding over the difference of working in academia and industry to the importance of aligning career choices with individual aptitudes and talents stimulated a large number of questions from the YM audience and was certainly a highlight of the event. 

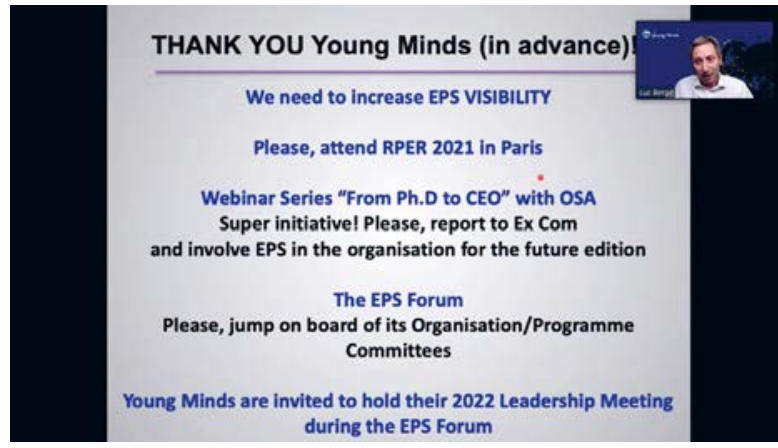

After the panel discussion the meeting transitioned to Gather Town, where the participants could engage in more informal and direct activities. During a speed networking event the delegates had the opportunity to refresh old connections and to create new ones within the YM community. Considering that the last direct exchange between the Action Committee and the sections took place during the leadership meeting 2019 it was also a great opportunity for the committee to get to know the new section officers in the established sections and to establish a relationship with the newly created sections. This was followed by a Physics Quiz, kindly provided by the hBar Omega Section Erlangen, in which the delegates mixed-up again, teamed in small groups and tested their knowledge, not only on physics but also on questions of popular science. After the physics quiz the official part of the meeting was concluded, but the Gather room remained open and many delegates stayed a bit longer and deepened their newly created connections.

Considering the large number of delegates, the many represented sections, the very active participation of the attendees over the full programme and the very positive feedback that the Action Committee received during and after the meeting, the virtual leadership meeting 2021 has been a large success. Hosting the meeting online allowed more delegates than usual to attend the meeting and reduced the logistical barrier for participation for delegates that might, for example, require a visa to travel. Hence the meeting provided a great opportunity to strengthen the connections to sections which are otherwise not frequently attending physical leadership meetings. Finally, for the sections that started their activity in 2020 and 2021 the meeting was a great chance to gain more insights into the programme structure and to connect with the network. However, even though the meeting has been a large success we are very much looking forward to connecting with the YM community physically again soon. The Action Committee just started with the preparation of the Leadership meeting 2022, which is planned to be co-located with the first EPS Forum. Thus 2022 will not only bring back physical meetings but will also bring Young Minds even closer to the broader European physics community.

\section{customized.}

Innovative Laser Solutions tailored

by our experts to advance your research!

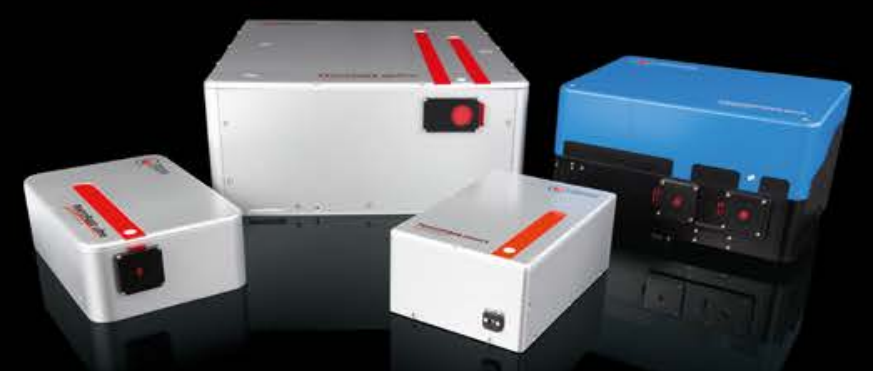

\section{FemtoFiber Laser Solutions}

Cutting-edge | Customized | Reliable | Simple \& Turn-key

\section{Your benefits:}

- Advanced laser systems that unlock the full potential of your application

- Advise and support from our technology and application experts

- Simple, reliable, and turn-key fiberlaser technology

Contact our experts and discuss your next laser system 